\title{
Capital as an Integrative Conceptualisation of Human Characteristics, Behaviour, and Outcomes Predicting Reproductive Success and Evolutionary Fitness
}

\author{
Tobias L. Kordsmeyer ${ }^{1}$ D
}

Received: 25 March 2021 / Revised: 20 July 2021 / Accepted: 22 July 2021 / Published online: 16 September 2021

(c) The Author(s) 2021

\begin{abstract}
According to evolutionary theory, human cognition and behaviour are based on adaptations selected for their contribution to reproduction in the past, which in the present may result in differential reproductive success and inclusive fitness. Because this depiction is broad and human behaviour often separated from this ultimate outcome (e.g., increasing childlessness), evolutionary theory can only incompletely account for human everyday behaviour. Moreover, effects of most studied traits and characteristics on mating and reproductive success turned out not to be robust. In this article, an abstract descriptive level for evaluating human characteristics, behaviour, and outcomes is proposed, as a predictor of long-term reproductive success and fitness. Characteristics, behaviour, and outcomes are assessed in terms of attained and maintained capital, defined by more concrete (e.g., mating success, personality traits) and abstract (e.g., influence, received attention) facets, thus extending constructs like embodied capital and social capital theory, which focuses on resources embedded in social relationships. Situations are framed as opportunities to gain capital, and situational factors function as elicitors for gaining and evaluating capital. Combined capital facets should more robustly predict reproductive success and (theoretically) fitness than individual fitness predictors. Different ways of defining and testing these associations are outlined, including a method for empirically examining the psychometric utility of introducing a capital concept. Further theorising and empirical research should more precisely define capital and its facets, and test associations with (correlates of) reproductive success and fitness.
\end{abstract}

Keywords Evolutionary theory $\cdot$ Reproductive success $\cdot$ Fitness $\cdot$ Capital $\cdot$ Human behaviour and characteristics

\section{Human Striving}

According to evolutionary theory, humans are executors of adaptations. Human cognition and behaviour are based on adaptations selected for their contribution to reproduction in the past, which may in the present result in differential reproductive success and eventually high inclusive fitness (Hamilton, 1964; Tooby \& Cosmides, 1990). What follows is that humans are engaged in dealing with adaptive problems in the environment, the strategies for dealing with these having been formed by natural selection and sexual selection (e.g., Puts, 2016). Accordingly, all human behaviour

Tobias L. Kordsmeyer

tob.kor@gmail.com

1 Department of Psychology, University of Göttingen: Georg-August-Universitat Göttingen, Gosslerstr. 14, 37073 Göttingen, Germany would be (more or less directly) aimed at solving adaptive problems including survival, gathering food, defending territory, or finding and retaining mates (Buss, 1997), because this leads to an increased evolutionary fitness ${ }^{1}$ by successfully reproducing and supporting subsequent offspring to reproduce later on. However, this depiction is very broad, and individuals' everyday behaviour is often very remote from it. Since evolutionary theory does not fully account for what humans strive for in daily life, the objective of this article is to outline a concept to be added to evolutionary theory, to be better able to map human behaviour from an evolutionary perspective.

Different theories have been put forth from an evolutionary perspective regarding human behaviour and striving. Famously, Maslow $(1943,1958)$ arranged diverse kinds

\footnotetext{
${ }^{1}$ In this article a definition of evolutionary fitness as "the expected representation of a replicating entity within a population at some distant point in the future" (p. 547, Coulson et al., 2006) is used.
} 
of human needs which ultimately motivate behaviour into a hierarchy. This hierarchy entails, from basic to highest needs, (1) physiological needs (e.g., hunger), (2) safety, (3) love and affection, (4) esteem (including the respect of others), and (5) self-actualisation. According to Maslow, higher-order needs are only aimed at once the needs below are satisfied. Maslow's hierarchy of needs has been updated by Kenrick and colleagues (2010) to render the hierarchy of needs being more in line with evolutionary theory. As one of the main revisions, self-actualisation was subsumed within esteem/respect and three newly added reproductive goals. The latter three reproductive goals under the realm of life history theory were suggested as the now highest needs, which are especially implicated in human striving for evolutionary fitness. Life history theory is a broad and prominent theoretical framework in evolutionary psychology, postulating trade-offs of allocating resources (such as time and energy) to diverse kinds of tasks and the development of traits in the pursuit of maximising evolutionary fitness, especially in the realm of mating and reproduction (e.g., Del Giudice et al., 2015). The three behavioural domains postulated by Kenrick and colleagues are highly implicated in these trade-offs and important mediators in striving for long-term reproductive success: mate acquisition, mate retention, and parenting. However, while they are certainly central in humans' pursuit of high evolutionary fitness and may well explain behaviours predicting reproductive fitness (e.g., in relation to status striving to win mates and many facets of nurturing behaviours), they still consider only part of the many and diverse everyday behaviours humans engage in. Also, while life history theory provides proximate explanations for the timing of and individual preferences for rather broad trade-offs and behaviours related to mating and reproduction, there is a gap regarding more specific, intermediate everyday behaviours (such as political engagement or health-related behaviours). These behaviours need to be focused on to be able to better explain reproductive success.

A central difficulty for biological explanations of human striving for a large quantity of offspring (reproductive success) is that humans do not seem to maximise their number of offspring and that fertility has been declining considerably in the last two centuries (Hopcroft, 2019; Sear et al., 2016). Especially in industrialised societies, relatively many people deliberately remain childless (with rates of childlessness increasing since the late 19th, and even more the mid-20th, century, Borgerhoff Mulder, 1998; Rowland, 2007). The fact that not all people seem to be trying to maximise the number of offspring may be explicable by people focussing not only on quantity but also the quality of offspring (e.g., survival, chances of own reproduction; Kenrick et al., 2010), in an attempt to optimise long-term reproductive success (Borgerhoff Mulder, 2000). However, deliberate childlessness, at least for individuals who are fertile and possess required resources including a mate, cannot be explained by people trying to maximise offspring quality. The declining fertility in the last 200 years or so and particularly the increasing childlessness since the mid-twentieth century remain a puzzle. Thus, it seems evolutionary theory may not be able to fully account for a range of human everyday behaviours, which seem remote from its main outcome measure, inclusive fitness. A central claim of this article is that humans evolved to invest in characteristics and outcomes (such as social relationships, wealth, or high-quality offspring) which collectively and indirectly may predict reproductive success, rather than to maximise their quantitative reproductive success per se. This tenet may help explain phenomena that would otherwise appear to be inconsistent with evolutionary theory.

In line with this, in previous studies, effects of single traits and characteristics on correlates of evolutionary fitness like reproductive success (or mating success, which is moderately strongly related to reproductive success, Puts et al., 2015) were mostly non-significant or, if significant, small or not robust. Some associations with mating and/or reproductive success have been found for physical attractiveness (e.g., Jokela, 2009; Pflüger et al., 2012; Rhodes et al., 2005; but see Hill et al., 2013 and Kordsmeyer et al., 2018 for null-findings), status measures (e.g., communitywide influence/prestige, political leadership, or wealth in men in a small-scale indigenous population, von Rueden \& Jaeggi, 2016; von Rueden et al., 2011), physical dominance (e.g., physical strength, muscularity, and body as well as vocal masculinity in men, Frederick \& Haselton, 2007; Hill et al., 2013; Kordsmeyer et al., 2018; Lassek \& Gaulin, 2009), intelligence (e.g., Greengross \& Miller, 2011; for an inverse association see Hopcroft, 2006), education (inversely, Hopcroft, 2006), income (in men but not women, Barthol et al., 2012; Hopcroft, 2006), height (positive linear and negative curvilinear effects in men, Nettle, 2002a; Stulp et al., 2012a; but see Hill et al., 2013 and Kordsmeyer et al., 2018 for null-effects; negative linear and curvilinear associations in women, Nettle, 2002b; Stulp et al., 2012b), and baseline testosterone levels (in men, as a potential proxy measure of health based on the immunocompetence hypothesis, e.g., Folstad \& Karter, 1992; Rantala et al., 2012). Some further effects appeared to be significant in a linear way in men, but not women (e.g., for height, Stulp et al., 2012b). Partly, these negligible effects are explicable by the potentially adaptive value of behaviours being highly dependent upon the (cultural) context in which behaviour occurs (e.g., the association between wealth and fertility is stronger in non-industrial compared to industrial societies, Kaplan et al., 2015). Within a specific context (e.g., depending on fertility rate, mating system, or availability of contraception), a trait or behaviour may be highly adaptive, whereas across contexts no noteworthy or unequivocal effects can be detected (e.g., Međedovića \& Kovačević, 
2020; Nettle, 2005; Smith \& Blumstein, 2008). Thus, single traits and characteristics should not robustly and universally predict (correlates of) evolutionary fitness.

Some of the above-mentioned traits and characteristics have been subsumed under the term embodied capital, defined as "knowledge, skills, or somatic traits that increase expected future fitness" (p. 1, von Rueden et al., 2015), which include physical strength, immune function, and knowledge, amongst others (Kaplan et al., 2003). However, empirical evidence of associations with mating or reproductive success is sparse yet. Lancaster and Kaplan (2010) presumed an association of reproductive success with health and feeding status in women and with resource-holding potential in men. Von Rueden and colleagues (2015) hypothesised causal pathways from embodied capital to reproductive success via prosocial traits and social status. A comprehensive investigation of effects of embodied capital on mating or eventual reproductive success is required.

A related stream of theorising focuses on benefits people seek and gain from social relationships. Social capital theory (e.g., Lin, 2001) suggests that resources embedded in social relationships, such as the quantity and quality of bonds with other people, provide them with benefits such as better jobs and earlier promotions, better mental health, or generally increasing socioeconomic status and accumulating human capital (economic resources embedded in humans, e.g., Bourdieu, 1986; Coleman, 1988; Lin, 2000; Savage \& Kanazawa, 2002). Empirical findings suggest positive effects of social capital on occupational and socioeconomic outcomes (e.g., Lin, 1999; Marsden \& Gorman, 2001). From an evolutionary perspective, social capital refers to any resource inhering in relationships that support people increasing their reproductive success as the ultimate aim (e.g., Kanazawa \& Savage, 2009). Specifically, social capital may augment reproductive success by increasing chances of survival, (socioeconomic) resources, mating success, and promoting offspring to sexual maturity (Kanazawa $\&$ Savage, 2009). However, empirical findings on associations of social capital with mating or reproductive success are rare (see Schülke et al., 2010 for comparative evidence suggesting enhancing effects of social bonds on reproductive success in male macaques and on offspring survival in female baboons; see von Rueden \& Jaeggi, 2016 for effects of variables such as wife quality and political influence on men's reproductive success in small-scale societies).

Thus, there is no complete picture of which characteristics, behaviour, and outcomes augment people's reproductive success and eventually evolutionary fitness. This can partly be ascribed to the fact that evolutionary fitness can only be estimated or measured indirectly (Sear et al., 2007) and even the assessment of lifetime reproductive success is difficult, due to the human lifespan being relatively long and reproduction being a rare event (compared to other primate species, e.g., van Schaik \& Burkart, 2010). Furthermore, associations of characteristics, behaviour, and outcomes typically studied in psychology and other social sciences with long-term reproductive success/evolutionary fitness could be mapped more precisely, especially if contemporarily humans may not explicitly strive to maximise their quantitative reproductive success. This would mean that a further level may be helpful theoretically, integrating different characteristics, behaviour, and outcomes like mating success as potential predictors of fitness.

What could such a level in-between look like? What could integrate and describe associations of human characteristics, behaviour, and outcomes with evolutionary fitness? Which concept(s) might usefully serve to describe human behaviour on the levels just below reproductive success and fitness (which should not be taken to imply, of course, that the latter two were on the same level)? The goal of this article is to propose a conceptualisation of such a level in-between, which may encompass and integrate a wide range of everyday human behaviours, implicated in their striving for a high long-term reproductive success and evolutionary fitness.

\section{Aim of This Article: Introducing the Concept of Capital}

Thus, there is potential for specifying what humans pursue from an evolutionary perspective. A more integrated construct on an abstract level may fill the gap between human characteristics and everyday behaviour, and evolutionary fitness in a comprehensive and parsimonious way. The objective of this article is to introduce an abstract concept of "capital," one level subordinate to the ultimate aim of evolutionary fitness (see Fig. 1). It is proposed that a large part of human characteristics, behaviour, and outcomes can be described on an abstract level by framing them

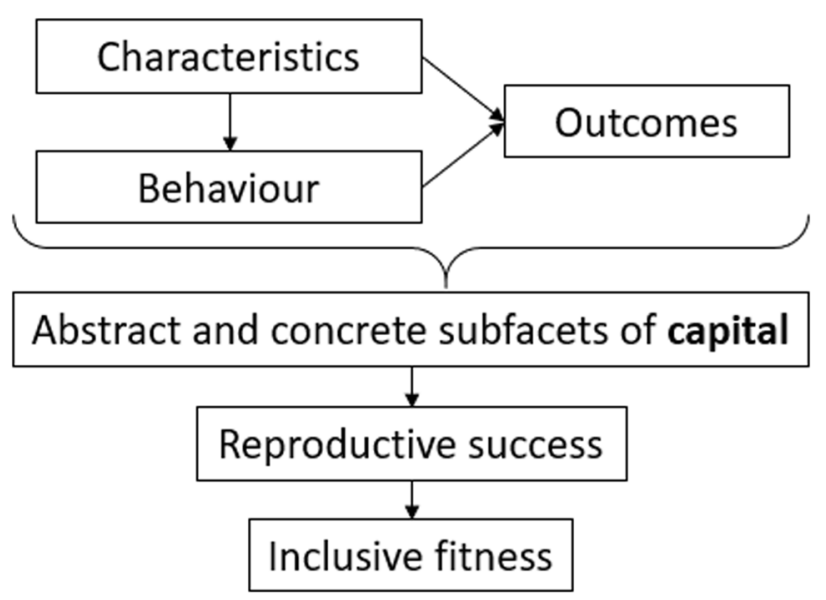

Fig. 1 The abstract concept of capital as a predictor of long-term reproductive success and inclusive fitness 
as indirectly striving to attain, accumulate, and maintain capital. Capital as an abstract construct would integrate and extend the concepts of embodied capital and social capital mentioned above, which include some but not all of the characteristics, behaviour, and outcomes relevant here. The proposed claim of humans indirectly striving for attaining capital attempts to fill the gap between common human behaviour and evolutionary fitness, in that it introduces capital as a unit for describing and evaluating human characteristics, behaviour, and outcomes as a concept one level below evolutionary fitness along with both abstract and concrete facets, which capture a range of relevant aspects of behaviour humans engage in regularly (Fig. 1).

This provides a way of assessing the adaptiveness of the capital facets an individual pursues and attains, dependent on personal and contextual factors, by quantifying a wide range of human behaviour in terms of specific outcomes (i.e., consequences of an individual's characteristics and behaviours which are related to evolutionary fitness). Capital facets would serve as subgoals and predictors of the ultimate goal of achieving a high long-term reproductive success and inclusive fitness (e.g., Hamilton, 1964; Kenrick et al., 2010). The amount of capital an individual accumulates should directly and positively predict eventual evolutionary fitness. The concept of capital could serve as an indicator for evolutionary success in terms of biological evolution but would also include measures of success regarding cultural evolution (e.g., Kleisner \& Tureček, 2017), at least insofar as these contribute to evolutionary fitness. This would generate new research questions on the adaptiveness of human characteristics, behaviour, and outcomes. In the following, the concept of capital will be defined in more detail by specifying both abstract and concrete facets as characteristics, behaviour, and outcomes that are assumed to be directly implicated in reallife social interaction and in the long-term pave the way for reproductive success and evolutionary fitness.

This proposal assumes that many single traits' associations with mating or reproductive success are of negligible size with many null findings and some nonlinear associations (as reviewed above). Accordingly, the conjecture in this article is not that all or most of the individual facets of capital robustly and linearly predict long-term reproductive success and evolutionary fitness (or at least mating success as a correlate). Instead, the idea suggested here is that these characteristics, behaviour, and outcomes, when combined and integrated on an abstract level, predict reproductive success and inclusive fitness, more strongly so in the longterm and over many generations (i.e., taking into account an individual's number of children, grandchildren, greatgrandchildren, and so on). Moreover, some effects of capital facets may not be linear, but curvilinear, as outlined above.

\section{What Does Capital Mean and Entail?}

The concept of capital entails a weighted integration of characteristics, behaviour, and outcomes predicting evolutionary fitness. This broad and general definition will be specified further in the following by describing both more concrete and more abstract facets of capital. More concrete facets of capital span specific characteristics and outcomes. A prominent example of attaining capital is raising healthy and viable offspring to sexual maturity, which in turn is successfully reproducing (eventually reaching a high reproductive success as the number of surviving children and grandchildren, e.g., Sear et al., 2007; Tooby et al., 2008; this could be measured by a proxy like mating success, which is supposed to be moderately strongly related to reproductive success, Puts et al., 2015). Further, developing and maintaining embodied capital can be considered a more concrete facet of capital (including physical attractiveness, health including immune function, intelligence, humour/creativity, and knowledge, adaptive personality traits, Kaplan et al., 2003; Lalumière et al., 2005; von Rueden et al., 2015), besides personal achievements like a high social status and assuming cultural/political roles (holding power), the latter two of which are inextricably linked (e.g., Pinker, 1999; von Rueden et al., 2008). Social status and power could be seen as both more abstract and more concrete facets of capital, depending on the definition and assessment. A more concrete kind of social status would be an objective measure (an individual's income, education, and occupational status, Adler et al., 2000), whereas popularity and prestige are more abstract kinds of status (e.g., van Vugt \& Tybur, 2015), related to representation and attention mentioned below. Further concrete facets of capital are monetary income and fortune (corresponding to economic capital in social capital theory, Bourdieu, 1986) and accumulating resources such as territory, food, and attracting sexual mates, which in turn are related to the other facets such as social status, cultural/ political roles, or mating success.

Finally, some of these facets of capital overlap with the facets and/or benefits of an individual's social capital (leaving aside the community-level definition of social capital, e.g., Lin, 2000), such as socioeconomic status, economic resources, mating success, and promoting offspring to sexual maturity (Kanazawa \& Savage, 2009; Savage \& Kanazawa, 2002). A further similarity is the general approach of both social capital theory and the concept of capital on characteristics and traits facilitating reproductive success and eventually inclusive fitness (e.g., Kanazawa \& Savage, 2009). In contrast, the concept of capital encompasses a wider array of characteristics, behaviour, and outcomes beyond those embedded in social relationships, including physical (money, 
territory) and human capital (economic resources embedded in humans, Savage \& Kanazawa, 2002, 2004). More generally, capital is defined as including any characteristics, behaviour, and outcomes as facets augmenting longterm reproductive success and inclusive fitness. Since social capital theory appears not to be evaluated well in terms of predicting reproductive success, this conceptualisation of capital extends social capital theory, hence rendering it measurable (see below).

\section{More Abstract Facets of Capital}

In an abstract sense, examples of capital are having influence (both biologically and culturally, concerning social status or power, i.e., influence on other people's behaviour and cognition) and being represented (receiving attention, for instance, in social interactions or (social) media, see Gilbert et al., 1995 for the related concept of social attention-holding power). These eventually augment overall attained capital and in the long-term should be linked to evolutionary fitness (cf. von Rueden \& Jaeggi, 2016). Such facets likely mediate associations of other, more concrete facets of capital, like increased social status, powerful positions, or (monetary) resources, with reproductive success and fitness.

In everyday settings, people's attention is biased towards people or situations with certain characteristics, such as attractive people, dangerous animals, or accidents (Bruner \& Goodman, 1947; see also Savage \& Kanazawa, 2004 for a similar conjecture from the perspective of social capital theory). These person and situational factors could be described as possessing characteristics especially relevant for people indirectly striving to gain and maintain capital. Attentional bias towards such people and situations can indirectly help people to gain capital, for example, by acquiring socially desirable information to support social gossiping and hence connecting with other people. Generally, in the social domain, typical forms of being represented include different manifestations of being attended to, such as receiving auditory and visual attention from other people in a conversation or when giving a talk. Attention becomes evident in media when one's works are read and recommended or shared (with effects beyond immediate economic monetary factors). Prominent contemporarily are "likes"/ referrals/shares in social media such as Facebook, Twitter, or TikTok (which could be referred to as platforms of evaluation, see below). The more often one's tweet (on Twitter) is liked and retweeted or the more likes one's post, photo, or video receives on Facebook or TikTok the higher is one's social impact and representation in this particular social medium (and possibly beyond). This may well relate to outcomes in the analogue social sphere, such as one's number of friends or close acquaintances, and the amount of social or professional support one receives, and might subsequently be associated with occupational success (because the latter is augmented by social skills and network size, for example). These, in turn, may predict desirable outcomes such as material resources and the likelihood of attracting and retaining a romantic partner, and later resources for successfully raising children. Thus, the amount of representation and attention an individual gains constitute a facet of capital (in an abstract sense), which in the long run should predict reproductive success and evolutionary fitness.

Some empirical evidence for an association between the amount of attention received and outcome measures is provided by Cheng and colleagues (2013). Participants using dominance and prestige strategies in a group interaction received greater visual attention from observers viewing the interactions and eventually reached higher influence in the group. Thus, attention may be a valid measure for people's status attainment, which in turn may be related to their longterm evolutionary fitness (von Rueden et al., 2011). Hence, abstract facets of capital such as influence, representation, and attention can serve as predictors for outcomes in everyday life in social and business domains and in the long term for evolutionary fitness.

\section{Capital: a Holistic, Descriptive Unit for Quantifying People's Characteristics and Outcomes}

This conceptualisation adds to evolutionary theory a descriptive level of capital as a unit of evaluation, one level below reproductive success and inclusive fitness (Fig. 1), enriching a broad level of analysis of human behaviour and achievements. Evolutionary theory is rendered better applicable to several contemporary and everyday phenomena, describing behavioural and motivational aspects which should have consequences on genetic and epigenetic levels. Finally, this approach contributes to bridging aspects of biological and cultural evolution (Kleisner \& Turecek, 2017).

Returning to the argument that evolutionary theory appears to be inconsistent with the observation of increasing childlessness in the past decades, by introducing the concept of capital it may be easier to understand that some people focus on other facets than a large quantity of offspring, which then would not positively predict quantitative reproductive success. Thus, while collectively a combination of facets of capital should be positively associated with long-term reproductive success, a specific selection of facets some people strive for (e.g., political power or occupational success) may result in deliberate childlessness and consequently lower evolutionary fitness for these individuals (see Kanazawa, 2001 for a claim that people prioritise the pursuit of proximate goals such as higher education or a demanding career 
over ultimate goals resulting in having children later in life or not at all). Such maladaptive or fitness-neutral behaviours may be augmented by evolutionarily novel circumstances like the availability of contraceptive methods, empowerment of women in industrialised countries, or drug usage (e.g., Nesse, 1994; Zethraeus et al., 2016). Still, capital and its facets may quantify people focussing on lower-level outcomes like social relationships or wealth, which in turn would lead to a higher (qualitative) reproductive success.

One may ask what the incremental benefit of such a capital concept is beyond established constructs like (social) status. While these certainly function as important life outcomes and should positively predict evolutionary fitness, they are often narrowly defined (e.g., objective social status, see above, Adler et al., 2000). The concept of capital is more complete, integrating different characteristics, behaviour, and outcomes, including social status, which collectively should more strongly predict long-term reproductive success and evolutionary fitness. Such a conceptualisation provides several benefits. Firstly, a holistic description of human behaviour and outcomes, as a predictor of long-term reproductive success and evolutionary fitness, would be added. Secondly, people's characteristics (e.g., embodied capital), resources, and achievements (e.g., social status, monetary income, and fortune) could be evaluated and quantified holistically, thus integrating biological and cultural achievements as predictors of evolutionary fitness. Hence, the concept of capital would serve as a broad, general unit for quantifying and assessing human characteristics, behaviour, and outcomes.

Further, one may perceive a strong overlap between facets of capital and another concept discussed in the literature, fitness components. Fitness components are defined as characteristics and outcomes of individuals (or organisms, more generally) giving rise to differences in fitness, such as life history traits (e.g., size at birth, growth pattern, age and size at maturity, rates of survival, and longevity, e.g., Orr, 2009; Steiner \& Tuljarparkur, 2012). However, while there is certainly some association between these and facets of capital, there is no complete overlap. On the one hand, while facets of capital encompass some of the fitness components proposed in the literature (e.g., mating success, some physical characteristics), they include further behaviours, characteristics, and outcomes not covered by fitness components (e.g., monetary income and fortune, status, and popularity). On the other hand, some fitness components do not constitute facets of capital, but are predicted by the latter (e.g., reproductive success, Steiner \& Tuljarpurkar, 2012). A further difference is that facets of capital are not necessarily genetically transmitted; cultural transmission for some facets is possible or even likely. Thus, the concept of capital can be considered a useful addition to evolutionary theory, complementing existing concepts such as fitness components predicting individuals' inclusive fitness.

Hence, one central benefit of the concept of capital is the possibility of holistically quantifying and evaluating people's characteristics, behaviour, and outcomes integrated into one index which should positively predict evolutionary fitness. Tooby and colleagues (2008) already proposed some more specific indices, termed internal regulatory variables, according to which humans can be evaluated, the measured characteristics of which may have direct consequences in social interactions. Examples include a sexual value index (indicating worth as a sexual partner), a formidability index (ability to inflict physical damage), and a kinship index (taking into account genetic relatedness influencing motivation to act towards others). These specific indices are supposed to be employed primarily (unconsciously) during social interactions and guide certain cognitive and behavioural decisions, considering costs and benefits of potential actions based on these indices (for the 3 exemplary indices, in terms of sexual behaviour, conflicts, or when interacting with kin of different degrees of relatedness, respectively; for a similar proposal and a specific discussion of domains of social value, including mate, descendant, kin, cooperative, and coalitional value, see Sugiyama, 2015). Further metrics already exist for tracking an individual's impact within a specific occupational field. For example, in academia, a researcher's work is evaluated in terms of the number of citations, or indices such as the h- or i10-index (e.g., Minasny et al., 2013). The holistic, descriptive construct of capital proposed here attempts to integrate such indices, further characteristics, behaviour, and concrete outcomes, from both private and professional domains relevant in terms of implicitly striving for high evolutionary fitness. One implication of this conceptualisation is that theoretically every behaviour of a given individual and every interaction between individuals can be evaluated and framed in terms of capital, with an individual involved either gaining or losing capital, being eventually positively or negatively related to one's evolutionary fitness (though effects may only be minimal for most single acts, of course). Consequently, this provides one answer to the question posed by Tooby and colleagues (2008) asking, "from an evolutionary perspective, what is social interaction for? What problems of survival, reproduction, and fitness promotion do individuals face when they live socially [...]?" (p. 256). Following the proposed construct of capital, social interactions are a platform for evaluating people, their characteristics and behaviour. In each social interaction, subtle behaviours signalling approval or disapproval can be detected. From an evolutionary perspective, the problems or challenges for individuals are to gain and maintain capital in social interactions (e.g., attention, approval, positive evaluation, which should lead to, amongst others, a higher social status, 
a larger accumulation of resources, for example, by attaining a greater occupational success, including social support when rearing children). All these factors should in the long-term and on average facilitate reproductive success and evolutionary fitness.

\section{Situations as Opportunities to Gain Capital and Platforms of Evaluation}

Relatedly, situations can be broadly conceptualised as opportunities (or platforms) to gain capital. By mastering challenges and threats people can accumulate capital in different domains (e.g., attracting a mate, gaining social status, extracting resources from others). How a given individual copes with environmental threats and challenges and eventually attains (or loses) capital depends strongly on situational factors (including characteristics of other people involved) and the individual's trait and state variables (including personality, health; for a similar account focussing on motives see Kenrick et al., 2010; for a similar discussion of personality and individual differences in the context of environments framed as adaptive problems see Buss, 2009b). Such individual decisions can be described under the umbrella of life history theory, with the baseline assumption that resources are limited and consequently there are trade-offs of how various resources are allocated (see above and Del Giudice et al., 2015). How these trade-offs are resolved in specific situations can be evaluated in terms of an individual's gained capital, strongly influenced by personal and contextual factors.

To render such a conceptualisation non-arbitrary, the specific threats and challenges of situations need to be defined, as well as the exact outcomes which are achieved in each situation (Buss, 2009a). While the former has been already discussed by Buss (2009a, 2009b) and situations were defined by adaptive problems which humans are confronted with frequently (e.g., attracting and retaining a mate, forming coalitions with peers, defending one's group from external threats such as outgroups), as yet there seems to lack an integrative and holistic way of assessing outcomes for such adaptive problems beyond the broad concept of evolutionary fitness. The facets of capital fill this gap by more directly connecting everyday challenges, behaviours, and their outcomes with evolutionary fitness, by adding a descriptive level of outcomes in-between. In such a framework, situations constitute opportunities to gain and maintain capital. Future work could in more detail analyse the relationship among specific situational challenges and affected facets of capital.

A related conjecture is that situations, their characteristics, and people within a particular situation function as facilitators of evaluation, in that they enable individuals to display, gain, and maintain capital (manifested as its facets) as well as to evaluate it in other people. The idea is that aspects of a situation or environment, which may include (the characteristics and behaviour of) other people present, trigger the presentation and assessment of a focal individual's characteristics and behaviour as facets of capital. Objective stimuli like music or a photo camera enrich situations and may hence trigger the evaluation of people's characteristics and behaviour. Music generally activates people (e.g., Ball, 2010), may in certain contexts motivate people to dance, through which people's physical and potentially further characteristics (e.g., personality traits, Fink et al., 2012; Hugill et al., 2011) become more salient. A photo camera and similar recording devices enable people to (implicitly or explicitly) demonstrate with whom and how they would like to be associated, for example, in social gatherings. Such recordings can be presented to other people (e.g., via social media), further fostering the evaluation of people, particularly in facets of capital like their social status, received attention, and representation, which may eventually impact their mating and reproductive success, and consequently fitness. For example, social media like WhatsApp, Twitter, Facebook, or TikTok may be seen as platforms for evaluation, providing situations in which people have the opportunity of showcasing their (favourable) traits, abilities, but also preferences and attitudes, which in turn are perceived and evaluated by peers. These evaluations are quantified in terms of likes, referrals, or shares, which relate to facets of capital such as influence, representation, status, and mating success, and in the long run should predict reproductive success and evolutionary fitness. Finally, other people present on such platforms (e.g., social media, photos, or situations where music is played) elicit and mediate the revealing of people's characteristics, behaviour, and hence their evaluation, and thus may also be seen as facilitators of evaluation. The extent of an individual's influence on other people's evaluation may be determined by their characteristics such as extraversion, in that more extraverted people are socially more salient, assertive, and hence trigger more and stronger opportunities for evaluating other people on these platforms. In future theorising and research, this conjecture of situations as platforms of evaluating people and potential implications need to be elaborated and specified.

A further possibility of framing human characteristics, behaviour, and outcomes based on the concept of capital is in terms of returns on investment (e.g., Frank, 2011). Individual differences in characteristics, behaviour, and outcomes (as facets of capital) would constitute the investment, which should in the long term result in differences in reproductive success and consequential inclusive fitness (the returns). Thus, it would need to be established for each facet of capital to what extent a certain degree of investment in this facet would lead to returns as (long-term) reproductive success and inclusive fitness. A (theoretically) suitable unit for quantifying the returns would be the number of surviving 
offspring or a measure of genetic representation in future generations (Coulson et al., 2006; Orr, 2009; Sear et al., 2007; for a measure of investment see capital scales below).

In turn, it may follow that not only can people, their characteristics, and outcomes be evaluated, but also that people are constantly evaluating other people as well as behavioural opportunities and available choices in their environment in terms of potential to gain and maintain capital. Presumably, this mostly happens implicitly and unconsciously. Examples of targets of such evaluation include romantic partners on the mating market ("Does (s)he meet my expected level of mate value? Or is (s)he even too attractive so that I had to fear intense competition?"), potential peers as friends and allies (whom to bond with and whom to avoid, see also Cottrell et al., 2007; Krems \& Conroy-Beam, 2020), or job options (e.g., earning potential, working conditions). This may involve third parties, for example, when someone reveals to friends a new romantic partner, and these friends ask for a photo of the new partner, to be able to assess the partner's attractiveness, which would in turn indicate part of the focal person's capital.

\section{Psychometric Assessment of Capital}

Effects of individual traits and outcomes on fitness (correlates) are mostly negligible and hardly reliable (e.g., Nettle, 2005; Smith \& Blumstein, 2008). An advantage of the concept of capital is that combined and cumulative effects of all facets, integrated into one capital variable, should be more reliably detectable than single effects. This is because adding up small individual effects should lead to a larger overall effect, which can then be pinpointed reliably. Such a combination of facets forms the new variable capital which allows to more accurately quantify and measure effects on fitness (correlates).

For a theoretical framework, it is important to be empirically testable to allow the definition and investigation of hypotheses (Brüne, 2002, see Table 1 for a list of specific hypotheses to test and refine the concept of capital). One way to quantify effects of (facets of) capital and hence to empirically test the suggested framework is to formulate and test point hypotheses (e.g., Witte \& Zenker, 2017). For illustration purposes, the following shows a compensatory model mapping combined and additive effects of (hypothetically independent) facets of capital on fitness (correlates):

$F=a \times A+b \times B+c \times C \ldots+e$ (where $F$ is fitness (correlate); $a, b, c, \ldots$ are parameter weights for the facets; $e$ is error; and $A, B, C, \ldots$ are parameters for the capital facets; capital facets should be $z$-standardised, and signed parameter weights should add up to 1 ; please note that in this simplified model, non-additive effects, such as negative interactions due to trade-offs, were left aside and would need to be considered in more refined models).

A compensatory hypothesis for the facets of capital can be tested by assuming a certain correlation between facets and subsequently predicting a regression line. For example, decreasing the parameter weight for one facet (e.g., income) may increase the parameter weight for another facet (e.g., physical attractiveness), keeping the value for fitness constant (compensatory model). A point hypothesis for the strength of the correlation between two facets based on $z$-standardised regression weights would be expressed as follows: $z_{1}=r_{1,2} \times z_{2}$. This equation provides a way of rendering the theoretical conceptualisation of capital empirically testable, and consequently of assessing how facets of capital could be combined and weighted to predict fitness (correlates). This equation could be used to test further hypotheses, such as sex differences on differential influences of capital facets on fitness (correlates; for point hypotheses and theory development see also Lakens et al., 2018).

One way to empirically examine the utility of introducing the abstract concept of capital is a procedure that determines and compares the model fit of different models (Kievit et al., 2011). Applied to the conceptualisation described in this article, a model including manifest facets of capital, a latent capital variable, and (pragmatically) a correlate of evolutionary fitness (e.g., reproductive success, Sear et al., 2007) as a dependent variable could be created. As a first step, the fit of this initial model would tell us whether the concept of capital could be integrated in a model of human characteristics, behaviour, and outcomes as predictors of (a correlate of) evolutionary fitness. Secondly, the inclusion of the latent capital variable's effects and resulting model fit could be examined. Thirdly and finally, model fit could be compared to a model completely excluding the latent capital variable. Given the model fit is at least as good when including the latent capital variable, compared to when excluding it, it can be concluded that at least psychometrically (in terms of model fit) the concept of capital is a useful addition to investigating pathways from human characteristics, behaviour, and outcomes to fitness (correlates).

\section{Capital Scales}

One way to explicitly quantify and measure the amount of capital an individual has gained would be to develop and administer a questionnaire, including self- and informantreports as well as objective measures. This could come in two versions, firstly assessing people's motivation to gain and maintain capital (facets), and secondly their attained overall capital (for each, including both abstract and more concrete facets). I will start by outlining concrete facets 


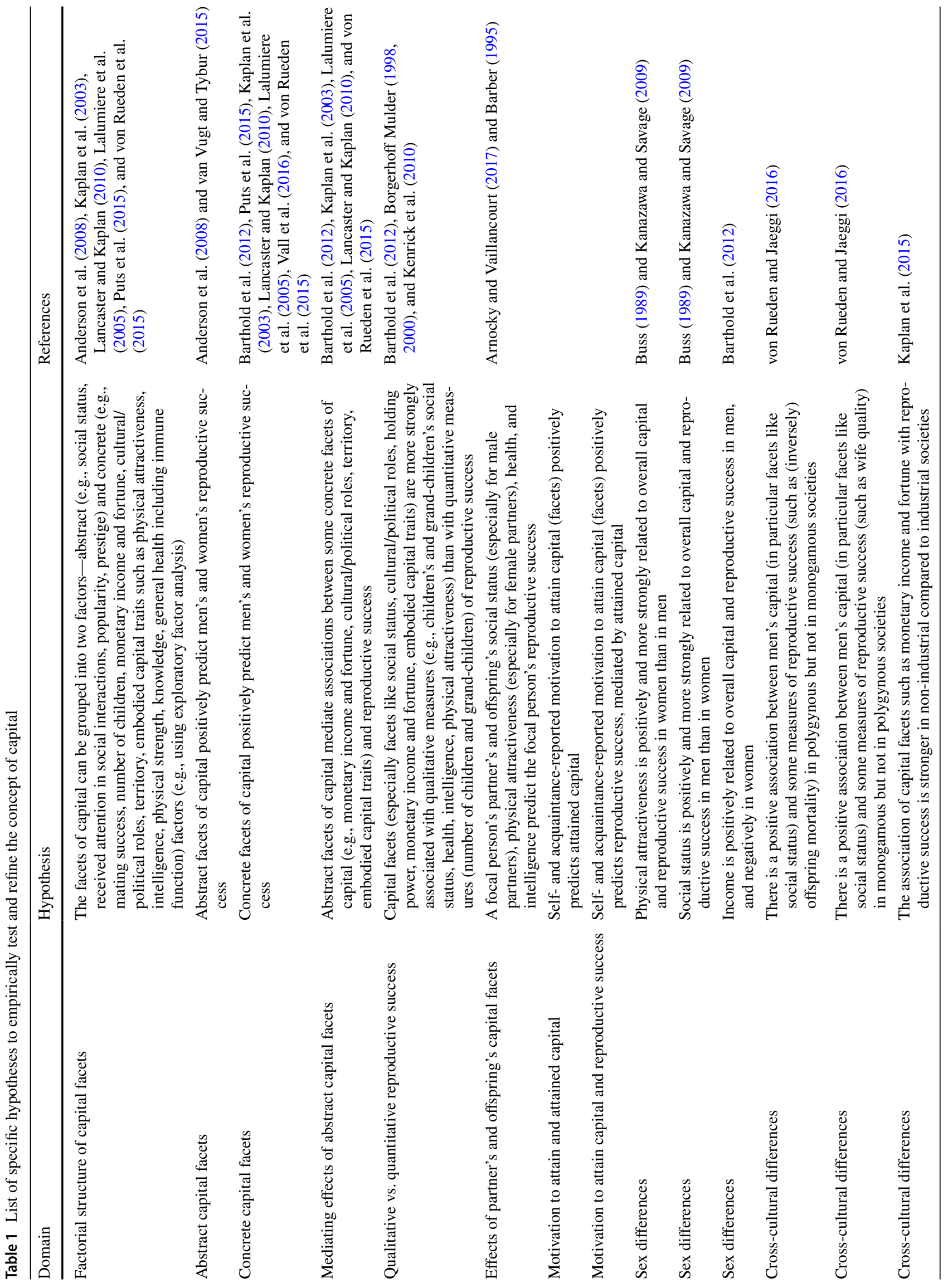


which would need to be included in such a capital scale, and first concerning an individual's attained capital. Crucially, the number of (surviving) children and grandchildren constitute a main indicator of an individual's evolutionary fitness and should be weighted strongly in such a capital scale. In case an individual has not reached the end of reproductive lifespan (menopause in women at around 50 years of age, towards the end of their overall lifespan for men, Harris et al., 2011; te Velde \& Pearson, 2002), a correlate measure such as mating success (e.g., number of sexual partners in the last year, Hill et al., 2013) could be employed, which is moderately strongly related to reproductive success (Puts et al., 2015). Moreover, since evolutionary fitness also depends on the survival and reproductive success of an individual's offspring, and (especially female) attractiveness is beneficial in terms of sexual selection (e.g., Arnocky \& Vaillancourt, 2017; Barber, 1995), it would be reasonable to include measures of one's partner's and offspring's social status, health, physical attractiveness, and potentially also intelligence as predictors of reproductive success. Further characteristics which would augment eventual evolutionary fitness are resources such as monetary income and fortune (Hopcroft, 2006; see Barthold et al., 2012 for a discussion of a potential sex difference), social status (Adler et al., 2000; Hopcroft, 2006), and certain personality traits and physical characteristics (e.g., embodied capital, see above, Kaplan et al., 2003; Lalumiere et al., 2005; for an investigation of seven dimensions of personality pathology on reproductive success see Vall et al., 2016; for associations between personality traits and different mating strategies see Strouts et al., 2017). Assessments of personality traits and physical characteristics could not only be conducted using selfreports but augmented by informant-reports, such as from acquaintances (Vazire, 2006).

As outlined above, more abstract facets encompass having an influence over others, being represented, and receiving attention. These could be assessed as subjective measures of social status (framed as prestige and dominance, e.g., using the MacArthur scale of subjective social status, Adler et al., 2000; peer-reported popularity, Hymel et al., 2011) or quantifying the amount of attention an individual receives in social interaction or (social) media (including Facebook, Twitter, TikTok, and Instagram, counting "likes" and "retweets"). Social influence could also be framed in terms of assuming leadership roles in social groups or being engaged in volunteering. Moreover, an individual's acquaintances could report on their influence and the amount of attention received in groups in which they are involved (e.g., Anderson et al., 2008). Abstract facets should only be assessed in conjunction with the more concrete facets of capital. The abstract facets may not be meaningful by themselves, because abstract facets can be considered manifestations of some of the concrete capital facets. For example, the amount of positively valued representation and attention (while partialling out negatively valued attention) a person has and receives should be predicted by personality and related traits, such as dominance, extraversion, and physical attractiveness, or skills and abilities (whether in arts, or social skills to be able to relate to other people).

Secondly, to assess people's motivation to gain capital (facets), similar dimensions as above would be rephrased in terms of an individual's willingness to strive towards outcomes as facets of capital. Sample items would be the following: "How many children are you willing or planning to have?", "Which highest level of education are you willing to strive for (below A levels, A levels, University degree, Ph.D.)?", "What are your career ambitions (e.g., with the categories not working, employed, in a lower-level leadership position, in a top-level leadership position)?", "What salary (per year) are you aiming for at the peak of your career?", "How much time and effort are you willing to invest in your health (e.g., doing sports and following a healthy nutrition?", or "How much time and effort are you willing to invest in your physical attractiveness (sports, fashion, beauty products)?" (e.g., on Likert scales from $1=$ not/nothing at all to $7=$ very much). In addition, such specific items could be enriched by further available scales on people's motivation, like the Unified Motive Scales (Schönbrodt \& Gerstenberg, 2012).

While such a scale assessing people's motivation may have some predictive validity for eventually attained overall capital, the association may only be moderate in size, however. This is because it may be hard for people to predict their actual life outcomes in domains such as health or reproductive success since these are at least partly beyond personal control (i.e., a person may be willing and planning to have many children and wishes to have some grandchildren later on as well, but their partner may think fewer children are enough, and these children in turn may not reproduce for personal or contextual reasons, beyond general biases such as self-serving biases and self-deception, e.g., von Hippel et al., 2005).

An important question surrounds the issue of how these components should be weighted to form one holistic indicator of attained capital. The measure of an individual's mating success should be weighted heavily since it is robustly related to reproductive success (e.g., Puts et al., 2015), which constitutes a main component of evolutionary fitness (in terms of the contribution to next generations' gene pools, Fisher, 1915; Orr, 2009). When weighing the influence of capital facets moderating variables need to be considered. For example, the association between mating and reproductive success has been shown to differ by sex (with a stronger correlation in men, e.g., Jokela et al., 2010) and cross-culturally depending on fertility rates, access to contraception, and polygyny (e.g., von Rueden \& Jaeggi, 2016). As a further example on sex differences, in both mate attraction and intrasexual selection, men 
typically engage in more overt competition (e.g., Hill et al., 2017; Kordsmeyer et al., 2018), whereas women use epigamic displays (enhancing their appearance) and indirect aggression (e.g., gossiping, excluding rivals, Arnocky \& Vaillancourt, 2017). Hence, in line with extant knowledge social status and dominance in men and physical attractiveness in women should be weighted more strongly (see also Kanazawa \& Savage, 2009).

\section{Ethical Considerations}

When such scales would be applied to assessing people and quantifying their attained capital or motivation to gain capital (facets) ethical considerations are crucial. For instance, people could be discriminated against depending on their attained capital, so that those lower in capital would suffer from limited rights and freedom. In case a large-scale assessment of individuals' attained capital would find consistent group differences it needs to be assured that cultural or ethnic groupings with on average lower attained capital are not discriminated against. Potential detrimental consequences and risks need to be discussed and possibly policies implemented so that such a construct would not be misused for discrimination.

\section{Inter-individual differences in which facets of capital are pursued, and how}

Scales on people's attained capital and their motivation to gain capital (facets) would also tap into inter-individual differences in striving for capital facets and eventual achievements. Interindividual differences in striving for and in attained capital should be influenced by an individual's characteristics, experiences, resources, and resulting biases and preferences. Tooby and colleagues (2008) proposed internal regulatory variables at work (as mentioned above), a computational architecture regulating approach and avoidance behaviours with an individual's brain computing the value of objects and subjects of interest. Life history theory is a suitable theoretical framework to explain both inter- and intra-individual differences, considering personal resources, characteristics, and contextual factors (e.g., environmental stability, Simpson et al., 2011). In the following, some examples of characteristics regarding inter-individual differences in indirectly striving for and attaining capital are discussed.

First, there should be sex differences in which facets of capital are pursued, and how. A straightforward example are mate preferences and mate choice. Whereas men seek a physically attractive, youthful partner (presumably as indicators of fertility and fecundability), women prefer a dominant, high-status male partner with a large amount of resources (e.g., Buss, 1989). Moreover, men tend to show a stronger focus on sexual and women more on nurturing goals (Kesebir et al., 2010). As a consequence of sexual dimorphism in reproductively relevant characteristics and behaviours (e.g., gamete size, female gestation, and lactation, differential parental care) it has been suggested that female sexuality is more valued compared to male sexuality, since the former represents a more limited resource (see Baumeister \& Vohs, 2004 for a discussion of how female but not male sexuality is endowed with values such as virginity, fidelity, and chastity on a marketplace of heterosexual couples; for instance, virginity is seen as a value for females but a stigma for men; for a consideration of age as a moderating variable on reproductive and marriage market value see Low, 2017). Generally, this perspective of ascribing value may help in understanding why sexuality is highly moralised in many, if not most, societies across the world (e.g., Brickell, 2009). With sexual behaviours there are large amounts of capital at stake (with subsequent responsibilities for both men and women; mainly assessed as number of children as a facet of capital), so that people are especially attentive and sensitive when evaluating these.

Two main dimensions of human social behaviour and personality may explain a large amount of variation in inter-individual differences in striving for capital facets, agency (also referred to as dominance) and communion (or nurturance, love, warmth, e.g., Wiggins, 1982). The underlying assumption and a hypothesis of this article is that all people (at least unconsciously and indirectly) strive to attain and maintain capital, but some do so more via the agency (manifested as getting ahead, gaining influence, power, Turan et al., 2014) and others more via the communion route (getting along with and relating to others, Turan et al., 2014). Take one abstract facet of capital, achieving a large influence. While it is obvious how individuals high in agency are striving for and may be succeeding to gain influence (see Anderson \& Kilduff, 2009 for a discussion of the effect of dominance on influence in groups), the case is not so clear for communion. Instead of trying to dominate and (explicitly) manipulate and influence others, people high in communion would achieve their (latent) goal of having an influence by connecting with and sometimes (covertly) manipulating others and impacting through their relationships with others (see von Rueden et al., 2015 for a similar reasoning on embodied capital and prosocial behavioural strategies). Which strategy an individual follows depends on other characteristics and available resources (e.g., sex, age, attractiveness, intelligence, formidability). The chosen strategy in interaction with characteristics and resources partly determines an individual's attained capital. For example, some people can afford to get ahead and dominate others and are still liked (respected and accepted in their group), whereas others try to get ahead too much (considering their skills and resources) and are thus rejected by peers. Hence, 
people with fewer resources and poorer skills should attain more capital by focussing on getting along with others (communion), whereas people with large amounts of resources and better skills will gain more capital by attempting to get ahead (agency). Both dimensions can be assessed (e.g., as personality traits using the Revised Interpersonal Adjective Scale, Wiggins et al., 1988) and related to overall attained capital as well as concrete and abstract facets (employing a capital scale), to elucidate inter-individual differences in pathways to capital.

Further (personality) traits, states, motivations, and available resources may explain inter-individual differences in indirectly striving for and gaining capital. For example, an individual's intelligence may predict to what extent one focuses on biological (such as a large number of offspring) or cultural facets of capital (e.g., political representation) potentially mediated by years of formal education. For example, in a longitudinal study following participants with above-average US-American SAT scores for more than three decades, individual differences in cognitive abilities predicted attained status (occupation and related aspects, such as patents and secured funding, Kell et al., 2013). Hence, personality characteristics can help to elucidate how and why individuals differ in pursuing specific facets of capital and which strategies they employ striving for these. Moreover, there is evidence of significant correlations between certain personality traits and other characteristics of a given individual. A potential mechanism is referred to as personality recalibration, which suggests that more attractive or formidable people tend to be more extraverted since they can afford to be more demanding and assertive in relationships (e.g., Lukaszewski \& Roney, 2011; but see von Borell et al., 2019 for mostly null-findings on associations between attractiveness, physical strength, and extraversion). Thus, overall, there is evidence that people who seem to have the highest potential of accumulating capital tend to do so actually. Moreover, beyond personality characteristics, genetic and epigenetic factors may play a role in inter-individual differences in capital preferences (for a study on genetic influences on value orientations see Kandler et al., 2016).

What is missing in the literature so far are studies on associations of the more abstract facets influence, representation, and attention with reproductive (or mating) success (but see above for findings on effects of status and prestige), which may also be seen as understudied fitness components (see above). These could be assessed using self- and informantreports and then related to reproductive success (ideally at the end of an individual's reproductive lifespan).

Moreover, on a slightly different level there are characteristics (mostly feelings and personality states) that may function as indicators of an individual's attained capital, such as happiness, satisfaction, and self-esteem. These associations should strongly depend on an individual's personal ambition (which in turn should be positively related to one's available resources, such as embodied capital), in that individuals with higher ambition should feel the same level of happiness, satisfaction, and self-esteem only at higher levels of attained capital, compared to someone with lower ambition. Happiness, satisfaction, and self-esteem may be bidirectionally linked with human motives (Lyubomirsky \& Boehm, 2010), in that they simultaneously signal the fulfilment of motives (in terms of attained capital in its various facets) and drive pursuing these as reward mechanisms (Lyubomirsky et al., 2005). Lyubomirsky and Boehm (2010) mention one exception, in that happiness is not directly and positively linked with parenthood. Here and in other studies, having and raising children may not be associated with increased happiness in the short term, but rather with long-term satisfaction and life fulfilment (Angeles, 2010; Lyubomirsky \& Boehm, 2010).

\section{Context-Dependence of Striving for Facets of Capital}

Beyond inter-individual differences in (striving for) capital facets, an important question surrounds the issue of how the exact facets of capital humans pursue manifest and differ across contexts (for a similar perspective on social capital theory see Kanazawa, 2001; Savage \& Kanazawa, 2004), such as different cultures and societies (e.g., collectivistic versus individualistic cultures, Hofstede, 1991). The primary facets of capital people strive for certainly differ depending on various contextual factors, such as socially shared experiences or environmental and political variables (Kesebir et al., 2010) as well as further characteristics and striving. Moreover, the way in which an individual's attained capital is related to evolutionary fitness should be influenced by cultural and social factors (e.g., which kinds of behaviours are approved/rewarded or rejected/punished). However, analysing in detail cultural and societal factors influencing human striving for capital facets and the relationship between attained capital and fitness would go beyond the scope of this article. At least it should be noted that a group's norms and laws provide boundary conditions affecting the ways in which its members indirectly strive for and attain capital and subsequently fitness. Because most of the studies cited here were conducted in contemporary, industrialised Western societies, the examples and effects proposed most likely are (more) valid in these kinds of societies (also referred to as WEIRD people, Henrich et al., 2010). The socioeconomic system prevalent in a society influences the approved forms of (and ways of striving for) capital facets. For example, monetary income and fortune as a main concrete facet of capital should especially be prevalent in capitalistic societies. Thus, the way in which individuals strive for capital facets and attain capital, and which facets of capital they pursue, depends on 
both inter-individual differences and contextual factors, such as socio-cultural variables.

\section{Transmission of Capital}

From an evolutionary standpoint, a crucial question is that of transmission, that is, how exactly is attained capital passed onto future generations? Partly, the propensity to gain and maintain capital should be propagated to future generations via natural selection, in that heritable components of traits that augment the attainment of capital (e.g., intelligence, physical attractiveness, dominance, health) are selected for under environmental and social selection pressures (Darwin, 1859; Kosova et al., 2010). Moreover, sexual selection in terms of competition with conspecifics for mates and mate choice by opposite-sex members, for example, based on attractive traits which may support offspring's likelihood of future reproduction, may play a role as well (e.g., Puts, 2016; Schaller et al., 2010). Concerning facets of capital, men with higher embodied capital and dominance may achieve higher reproductive success, partly attributable to female mate choice for high-status, dominant men (von Rueden \& Jaeggi, 2016). Beyond genetic transmission, there likely is an influence of epigenetic mechanisms in the passing on of capital to future generations (e.g., Kenrick et al., 2010). Both detrimental (e.g., chronic stressors) and beneficial influences (e.g., social support) may transmit to offspring and affect their chances of attaining and maintaining capital. Moreover, genetic and non-genetic cultural transmission may interact, termed gene-culture coevolution or niche-construction (Laland et al., 2000; Richerson \& Boyd, 2005). For example, natural and sexual selection are embedded in social and cultural settings, whereas cultural activities are constrained and promoted by genetic factors (e.g., Gintis, 2011). Applying this to the concept of capital, attained capital in facets in the cultural domain (e.g., social status, influence, or attention) may augment success in genetic transmission (e.g., reproductive success) while at the same time genetic factors (e.g., heritable personality traits) may enhance or restrict cultural achievements. Thus, the concept of capital and its facets can be applied to different levels of genetic and nongenetic transmission, and further theorising and research are required to understand the different processes and their relationships more accurately.

\section{Further Discussion and Limitations}

One crucial characteristic of psychological theories and hypotheses is falsifiability; that is, they are defined to be refutable (Popper, 1959). While the herein proposed construct of capital and its facets may not be easily falsifiable in terms of predicting evolutionary fitness (since directly measuring the latter according to the above-mentioned definition is difficult; for a discussion of fitness measures see for example Benton \& Grant, 2000; Orr, 2009), it certainly is falsifiable when employing a correlate measure of evolutionary fitness like reproductive success (number of children, and possibly of grandchildren, at the end of reproductive lifespan, Sear et al., 2007). However, effects of some of the mentioned predictor variables (e.g., personality traits, attractiveness) can be expected to be rather weak over a few generations only, and that a significant effect on fitness would only emerge after several generations (i.e., more extraverted or more attractive individuals may not have a larger number of children, but these children's future offspring should have a greater rate of survival and reproduction, on average; for effects of personality traits on reproductive success over two generations see Međedović et al., 2018). Still, relating attained capital and its facets to reproductive success over one (or ideally two or more) generation should already result in, at least small, positive associations (based on evidence outlined above; see above for a discussion of a psychometric assessment of capital, its facets and associations with fitness correlates).

An overall index of capital as a combination of its facets should be positively related to long-term reproductive success and evolutionary fitness. It can hence be positioned one level below the latter, connecting fitness with everyday behaviour and outcomes, and functioning as an indicator of adaptiveness (Fig. 1).

An important qualification is that people are not constantly overtly striving for capital facets (e.g., Peterson \& Park, 2010). Relevant here is the principle of least effort (Clark, 1996) which suggests that people try to be "just good enough" and to complete a task "just soon enough," presumably to save energy and resources. This implies that not each and every single act can be evaluated in terms of directly being related to gaining and maintaining capital facets, but rather that an individual's behaviour must be seen holistically over a longer time frame since people strive for efficiency which may come across as laziness (see also Ackerman \& Bargh, 2010).

\section{Further Applications and Implications}

An implication of the concept of capital may be that people are selected to be biased to attending to situations and people high in capital facets (e.g., prestigious or attractive people or those with unusual characteristics, unexpected social happenings, and dangerous situations like accidents or interpersonal conflict), since acquiring such knowledge and information is inherently adaptive (Bruner \& Goodman, 1947, see also above). Perceived (facets of) capital of interaction partners or situations may subsequently activate evolutionarily 
shaped needs and motivate behaviours (e.g., Neuberg et al., 2005). This bias in perception may be functional in various ways, for example, in social learning from successful (high-status) individuals, but also in trying to avoid apparently unsuccessful behaviour or outcomes. Moreover, such a bias may support people in gathering socially valuable information (e.g., on relevant socio-cultural news or facts) which in turn could help people bond with others (i.e., form friendships, coalitions, and romantic relationships). Further research should try to investigate such a bias in more detail, for instance, using methodologies from research on attentional biases (e.g., dot-probe detection task, Townshend \& Duka, 2001) and examining emotional states as potential processes (e.g., Ketelaar \& Tung Au, 2003).

Another straightforward application would concern people's job satisfaction. A central influence on people's satisfaction at work is how self-determined they feel, how much control they perceive to be able to exert over their situation at work, also referred to as having an internal locus of control (e.g., Judge \& Bono, 2001). This is in line with people striving to gain and maintain capital facets, such as having an influence. The increased satisfaction could be parsimoniously explained by people's emotions and affects rewarding behaviours supportive in gaining capital. If an employee's (or self-employed person's, or any other worker's, for that matter) job tasks and responsibilities allow them to have an influence (leading to social attention, monetary success like turnover, or acquired customer relations) job satisfaction should accordingly be higher compared to jobs in which they are restricted in the potential to have influence. This should in turn interact with characteristics and skills, with a better person-environment fit (Kristof-Brown \& Guay, 2011) in terms of personal characteristics, job tasks, and responsibilities leading to higher job satisfaction, partly attributable to higher gained influence. Similar reasoning may be applicable to people's satisfaction with their personal relationships. If someone perceives that their interaction partner is open for suggestions and responsive to actions and behaviour, this may improve relationship satisfaction, potentially based on the fulfilled need of having an influence. On the other hand, if someone seems completely unaffected by an interaction partner's suggestions and behaviours, this would likely reduce relationship intensity and quality (at least over multiple occasions). Overall, gaining influence, whether in a professional or private setting, is a central (not necessarily conscious) aim and should strongly relate to people's satisfaction in different contexts.

A further application of this proposal of human striving for capital facets concerns criminal behaviour (cf. Savage \& Kanazawa, 2002 for a social capital theoretical perspective on criminal behaviour). Though criminal behaviour is legally and socially rejected and often formally punished in most, if not all, societies, its prevalence is still high around the globe (e.g., Statista, 2018). The conceptualisation of capital enables to frame criminality as an alternative strategy of trying to gain capital, which may well be successful dependent on contextual factors (such as environmental instability, prevalence of other criminals in a given population, e.g., Figueredo et al., 2011). It has already been proposed and found empirically that criminal behaviour may function as an alternative mating strategy marked by low parental investment (Yao et al., 2014). In this study using population registers overall encompassing nearly five million people, criminal offenders achieved a higher reproductive success relative to non-criminals, partly explicable by having children from multiple partners. Criminal offenders may thus (implicitly) still aim for the ultimate goal of high evolutionary fitness, while employing different strategies and focussing on different facets of capital compared to non-offenders, potentially in interaction with their specific personality traits, other characteristics, and available resources (e.g., neurological deficits or unstable childhood, Raine et al., 1996). Examples of capital facets which criminal offenders may strive for primarily include accumulating large amounts of money (amongst others for mate attraction), occupying a specific niche in terms of prestige and social status (amongst fellow criminals), a large quantity of offspring (Yao et al., 2014), and in some cases formidability (to threaten rivals or potential victims). Some of these are captured by a fast life-history strategy (e.g., Dunkel et al., 2013). Regarding the more abstract facets of capital, criminal offenders may similarly strive for influence (on other people, including victims, which are often close relatives or friends) and being represented (receiving attention), only employing different strategies than non-offenders. This proposal of capital helps to elucidate why prison sentences are such a strong punishment. An imprisoned person is highly restricted in opportunities of gaining capital, because one is only allowed to act within the limits of the prison and not to follow regular, self-chosen work and only rarely to interact with peers or family. Thus, the proposed concept of capital with its facets provides a straightforward way of describing the aims and outcomes of criminal offenders' alternative behavioural strategies. Understanding criminals' behaviour as striving for influence, representation, and attention may help in improving intervention programmes, for example, by supporting them in achieving their aims using socially more acceptable behaviours.

Finally, this conceptualisation of human striving for capital facets may have implications for how politicians and policymakers, amongst others, react to and intervene in current crises, such as Europe's migration crisis or (purportedly 
human-made) global climate change. It is important to recognise that humans are striving for prevalent and relevant facets of capital, and that interventions should not try to restrict this, but attempt to steer humans striving towards facets of capital that are more sustainable, healthier for both environment and society (e.g., for alternatives to the capitalist growth economy see Paech, 2012). Hence, instead of trying to undermine striving for the accumulation of capital, interventions could aim at promoting more sustainable kinds of capital. Examples may include promoting electric cars (assuming they would be environmentally friendlier if entirely running on renewable energy) as status symbols and hence indicators of capital, or shortening minimum working hours in order to enable people to focus on socio-cultural instead of commercial facets of capital.

\section{Suggestions for Future Research}

As this article provides a first conceptualisation of the idea of assessing human characteristics, behaviour, and outcomes in terms of capital and its more concrete and more abstract facets, future empirical and theoretical studies should attempt to flesh out details (see Table 1 for a list of specific predictions as a basis for empirically testing and refining the concept). For example, the two capital scales (on striving for capital facets and attained capital) could be constructed and validated within different socio-cultural contexts. Associations between these two measures (in terms of predictive validity of motivation to attain capital facets for eventually attained capital facets) or with purportedly convergent and divergent constructs (e.g., physiological measures, such as testosterone levels, e.g., Eisenegger et al., 2011) to assess construct validity could be investigated. Moreover, unique predictive validity (beyond existing measures of human motives, goals, and outcomes) could be assessed by examining relationships between measures of the facets of capital and correlates of evolutionary fitness (ideally long-term reproductive success). The latter would also provide insights into how the facets should be weighted concerning their prediction of overall capital and eventually inclusive fitness. Such studies could be performed on individuals towards the end of their reproductive lifespan in a cross-sectional design or preferably longitudinally, assessing outcomes in terms of reproductive success predicted by facets of capital measured both decades before (facets like embodied capital) and towards the end of an individual's reproductive lifespan (facets such as accumulated wealth, number of offspring raised to sexual maturity, offspring health, and intelligence).

\section{Conclusion}

In this article, the implementation of a new abstract descriptive level is proposed for evaluating human characteristics, behaviour, and outcomes, one level below the ultimate aim of long-term reproductive success and evolutionary fitness. In particular, human striving can be assessed in terms of attained and maintained capital. Capital is an abstract, integrative construct, defined by facets grouped into more concrete and more abstract characteristics, behaviour, and outcomes. More concrete facets include primarily quantifiable capital facets such as the number of offspring (raised to sexual maturity), embodied capital (e.g., intelligence, attractiveness, health, adaptive personality traits), education, (objective) social status, and money (income, fortune). Abstract facets comprise influence, being represented, and receiving attention, and can be measured as (subjective) social status, prestige, or assuming socio-cultural roles, for example. These facets partly overlap with and extend those of social capital according to social capital theory. The main conjecture is that a certain combination of facets of capital should strongly predict long-term reproductive success and hence inclusive fitness. Attained capital may not be strongly related to quantitative reproductive success within one generation, but to reproductive success over many generations. One implication is that people's characteristics, behaviour, and outcomes can be evaluated regarding the likelihood of increasing success in gaining capital and accordingly evolutionary fitness. Moreover, from this perspective situations can be framed as opportunities to gain capital and platforms for evaluating capital. Crucially, further theorising and empirical research are required to more precisely define capital, its facets, and to test associations with (correlates of) reproductive success and inclusive fitness.

Funding Open Access funding enabled and organized by Projekt DEAL.

\section{Declarations}

Conflict of interest The authors declare no competing interests.

Open Access This article is licensed under a Creative Commons Attribution 4.0 International License, which permits use, sharing, adaptation, distribution and reproduction in any medium or format, as long as you give appropriate credit to the original author(s) and the source, provide a link to the Creative Commons licence, and indicate if changes were made. The images or other third party material in this article are included in the article's Creative Commons licence, unless indicated otherwise in a credit line to the material. If material is not included in the article's Creative Commons licence and your intended use is not 
permitted by statutory regulation or exceeds the permitted use, you will need to obtain permission directly from the copyright holder. To view a copy of this licence, visit http://creativecommons.org/licenses/by/4.0/.

\section{References}

Ackerman, J. M., \& Bargh, J. A. (2010). The purpose-driven life: Commentary on Kenrick et al. (2010). Perspectives on Psychological Science, 5, 323-326. https://doi.org/10.1177/1745691610369472

Adler, N. E., Epel, E. S., Castellazzo, G., \& Ickovics, J. R. (2000). Relationship of subjective and objective social status with psychological and physiological functioning: Preliminary data in healthy, White women. Health Psychology, 19, 586-592. https:// doi.org/10.1037/0278-6133.19.6.586

Anderson, C., Ames, D. R., \& Gosling, S. D. (2008). Punishing hubris: The perils of overestimating one's status in a group. Personality and Social Psychology Bulletin, 34, 90-101. https://doi.org/10. 1177/0146167207307489

Anderson, C., \& Kilduff, G. J. (2009). Why do dominant personalities attain influence in face-to-face groups? The competence-signaling effects of trait dominance. Journal of Personality and Social Psychology, 96, 491-503. https://doi.org/10.1037/a0014201

Angeles, L. (2010). Children and life satisfaction. Journal of Happiness Studies, 11, 523-538. https://doi.org/10.1007/s10902-009-9168-z

Arnocky, S., \& Vaillancourt, T. (2017). Sexual competition among women: A review of the theory and supporting evidence. In M. L. Fisher (Ed.), The Oxford handbook of women and competition (pp. 25-39). Oxford, UK: Oxford University Press. https://doi. org/10.1093/oxfordhb/9780199376377.013.3

Ball, P. (2010). The music instinct: How music works and why we can't do without it. Oxford University Press.

Barber, N. (1995). The evolutionary psychology of physical attractiveness: Sexual selection and human morphology. Ethology and Sociobiology, 16, 395-424. https://doi.org/10.1016/01623095(95)00068-2

Barthold, J. A., Myrskylä, M., \& Jones, O. R. (2012). Childlessness drives the sex difference in the association between income and reproductive success of modern Europeans. Evolution and Human Behavior, 33, 628-638. https://doi.org/10.1016/j.evolhumbehav. 2012.03.003

Baumeister, R. F., \& Vohs, K. D. (2004). Sexual economics: Sex as female resource for social exchange in heterosexual interactions. Personality and Social Psychology Review, 8, 339-363. https:// doi.org/10.1207/s15327957pspr0804_2

Benton, T. G., \& Grant, A. (2000). Evolutionary fitness in ecology: Comparing measures of fitness in stochastic, density-dependent environments. Evolutionary Ecology Research, 2, 769-789.

Bourdieu, P. (1986). Forms of capital. In J. G. Richardson (Ed.), Handbook of theory and research for the sociology of education (pp. 242-258). Greenwood.

Borgerhoff Mulder, M. (1998). The demographic transition: Are we any closer to an evolutionary explanation? Trends in Ecology \& Evolution, 13, 266-270. https://doi.org/10.1016/S0169-5347(98) 01357-3

Borgerhoff Mulder, M. (2000). Optimizing offspring: The quantityquality tradeoff in agropastoral Kipsigis. Evolution and Human Behavior, 21, 391-410. https://doi.org/10.1016/S1090-5138(00) 00054-4

Brickell, C. (2009). Sexuality, morality and society. In G. Byrnes (Ed.), The New Oxford history of New Zealand (pp. 465-486). Oxford University Press.

Brüne, M. (2002). Toward an integration of interpersonal and biological processes: Evolutionary psychiatry as an empirically testable framework for psychiatric research. Psychiatry: Interpersonal and Biological Processes, 65, 48-57. https://doi.org/10.1521/ psyc.65.1.48.19759

Bruner, J. S., \& Goodman, C. C. (1947). Value and need as organizing factors in perception. The Journal of Abnormal and Social Psychology, 42, 33-44. https://doi.org/10.1037/h0058484

Buss, D. M. (1989). Sex differences in human mate preferences: Evolutionary hypotheses tested in 37 cultures. Behavioral and Brain Sciences, 12, 1-14. https://doi.org/10.1017/S0140525X00023992

Buss, D. M. (1997). Human social motivation in evolutionary perspective: Grounding terror management theory. Psychological Inquiry, 8, 22-26. https://doi.org/10.1207/s15327965pli0801_3

Buss, D. M. (2009a). An evolutionary formulation of person-situation interactions. Journal of Research in Personality, 43, 241-242. https://doi.org/10.1016/j.jrp.2008.12.019

Buss, D. M. (2009b). How can evolutionary psychology successfully explain personality and individual differences? Perspectives on Psychological Science, 4, 359-366. https://doi.org/10.1111/j. 1745-6924.2009.01138.x

Cheng, J. T., Tracy, J. L., Foulsham, T., Kingstone, A., \& Henrich, J. (2013). Two ways to the top: Evidence that dominance and prestige are distinct yet viable avenues to social rank and influence. Journal of Personality and Social Psychology, 104, 103-125. https://doi.org/10.1037/a0030398

Clark, H. H. (1996). Using language. Cambridge University Press. https://doi.org/10.1017/CBO9780511620539

Coleman, J. S. (1988). Social capital in the creation of human capital. American Journal of Sociology, 94, S95-S120. https://doi. org/10.1086/228943

Cottrell, C. A., Neuberg, S. L., \& Li, N. P. (2007). What do people desire in others? A sociofunctional perspective on the importance of different valued characteristics. Journal of Personality and Social Psychology, 92, 208-231. https://doi.org/10.1037/ 0022-3514.92.2.208

Coulson, T., Benton, T. G., Lundberg, P., Dall, S. R. X., Kendall, B. E., \& Gaillard, J. M. (2006). Estimating individual contributions to population growth: Evolutionary fitness in ecological time. Proceedings of the Royal Society B: Biological Sciences, 273, 547-555. https://doi.org/10.1098/rspb.2005.3357.

Darwin, C. (1859). On the origin of species by means of natural selection. London, UK: Murray.

Del Giudice, M., Gangestad, S. W., \& Kaplan, H. S. (2015). Life history theory and evolutionary psychology. In D. M. Buss (Ed.), The Handbook of Evolutionary Psychology (Vol. 1: Foundations; pp. 88-114). Hoboken, New Jersey: John Wiley \& Sons. https://doi.org/10.1002/9781119125563.evpsych102

Dunkel, C. S., Mathes, E., \& Beaver, K. M. (2013). Life history theory and the general theory of crime: Life expectancy effects on low self-control and criminal intent. Journal of Social, Evolutionary, and Cultural Psychology, 7, 12-23. https://doi.org/ 10.1037/h0099177

Eisenegger, C., Haushofer, J., \& Fehr, E. (2011). The role of testosterone in social interaction. Trends in Cognitive Sciences, 15, 263-271. https://doi.org/10.1016/j.tics.2011.04.008

Figueredo, A. J., Gladden, P. R., \& Hohman, Z. (2011). The evolutionary psychology of criminal behavior. In S. C. Roberts (Ed.), Applied evolutionary psychology (pp. 201-221). Oxford, UK: Oxford University Press. https://doi.org/10.1093/acprof: oso/9780199586073.003.0013

Fink, B., Weege, B., Flügge, J., Röder, S., Neave, N., \& McCarty, K. (2012). Men's personality and women's perception of their dance quality. Personality and Individual Differences, 52, 232-235. https://doi.org/10.1016/j.paid.2011.10.008

Fisher, R. A. (1915). The evolution of sexual preference. The Eugenics Review, 7, 184-192. 
Folstad, I., \& Karter, A. J. (1992). Parasites, bright males, and the immunocompetence handicap. The American Naturalist, 139, 603-622. https://doi.org/10.1086/285346

Frank, S. A. (2011). Natural selection. I. Variable environments and uncertain returns on investment. Journal of Evolutionary Biology, 24, 2299-2309. https://doi.org/10.1111/j.1420-9101.2011. 02378.x

Frederick, D. A., \& Haselton, M. G. (2007). Why is muscularity sexy? Tests of the fitness indicator hypothesis. Personality and Social Psychology Bulletin, 33, 1167-1183. https://doi.org/10. 1177/0146167207303022

Gilbert, P., Price, J., \& Allan, S. (1995). Social comparison, social attractiveness and evolution: How might they be related? New Ideas in Psychology, 13, 149-165. https://doi.org/10.1016/0732-118X(95) 00002-X

Gintis, H. (2011). Gene-culture coevolution and the nature of human sociality. Philosophical Transactions of the Royal Society of London B: Biological Sciences, 366, 878-888. https://doi.org/ 10.1098/rstb.2010.0310

Greengross, G., \& Miller, G. (2011). Humor ability reveals intelligence, predicts mating success, and is higher in males. Intelligence, 39, 188-192. https://doi.org/10.1016/j.intell.2011.03. 006

Hamilton, W. D. (1964). The genetical evolution of social behaviour. II. Journal of Theoretical Biology, 7, 17-52. https://doi.org/10. 1016/0022-5193(64)90039-6

Harris, I. D., Fronczak, C., Roth, L., \& Meacham, R. B. (2011). Fertility and the aging male. Reviews in Urology, 13, e184-e190.

Henrich, J., Heine, S. J., \& Norenzayan, A. (2010). The weirdest people in the world? Behavioral and Brain Sciences, 33, 61-83. https://doi.org/10.1017/S0140525X0999152X

Hill, A. K., Bailey, D. H., \& Puts, D. A. (2017). Gorillas in our midst? Human sexual dimorphism and contest competition in men. In M. Tibayrenc and F. J. Ayala (Eds.), On Human Nature: Biology, Psychology, Ethics, Politics, and Religion (pp. 235-249). New York: Academic Press. https://doi.org/10. 1016/B978-0-12-420190-3.00015-6

Hill, A. K., Hunt, J., Welling, L. L., Cárdenas, R. A., Rotella, M. A., Wheatley, J. R., Dawood, K., Shriver, M. D., \& Puts, D. A. (2013). Quantifying the strength and form of sexual selection on men's traits. Evolution and Human Behavior, 34, 334-341. https://doi.org/10.1016/j.evolhumbehav.2013.05.004

Hofstede, G. (1991). Organizations and cultures: Software of the mind. McGrawHill.

Hopcroft, R. L. (2006). Sex, status, and reproductive success in the contemporary United States. Evolution and Human Behavior, 27, 104-120. https://doi.org/10.1016/j.evolhumbehav.2005. 07.004

Hopcroft, R. L. (2019). Is fertility after the demographic transition maladaptive? Journal of Biosocial Science, 51, 157-176. https://doi.org/10.1017/S0021932018000032

Hugill, N., Fink, B., Neave, N., Besson, A., \& Bunse, L. (2011). Women's perception of men's sensation seeking propensity from their dance movements. Personality and Individual Differences, 51, 483-487. https://doi.org/10.1016/j.paid.2011.05. 002

Hymel, S., Closson, L. M., Caravita, S., \& Vaillancourt, T. (2011). Social status among peers: From sociometric attraction to peer acceptance to perceived popularity. In P. K. Smith \& C. H. Hart (Eds.), The Wiley-Blackwell Handbook of Childhood Social Development (pp. 375-392). Malden, MA: Wiley/Blackwell. https://doi.org/10.1002/9781444390933.ch20

Jokela, M. (2009). Physical attractiveness and reproductive success in humans: Evidence from the late 20th century United States. Evolution and Human Behavior, 30, 342-350. https://doi.org/10. 1016/j.evolhumbehav.2009.03.006
Jokela, M., Rotkirch, A., Rickard, I. J., Pettay, J., \& Lummaa, V. (2010). Serial monogamy increases reproductive success in men but not in women. Behavioral Ecology, 21, 906-912. https://doi. org/10.1093/beheco/arq078

Judge, T. A., \& Bono, J. E. (2001). Relationship of core selfevaluations traits-Self-esteem, generalized self-efficacy, locus of control, and emotional stability -With job satisfaction and job performance: A meta-analysis. Journal of Applied Psychology, 86, 80-92. https://doi.org/10.1037/0021-9010.86.1.80

Kanazawa, S. (2001). De gustibus est disputandum. Social Forces, 79, 1131-1162. https://doi.org/10.1353/sof.2001.0013

Kanazawa, S., \& Savage, J. (2009). An evolutionary psychological perspective on social capital. Journal of Economic Psychology, 30, 873-883. https://doi.org/10.1016/j.joep.2009.08.002

Kandler, C., Gottschling, J., \& Spinath, F. M. (2016). Genetic and environmental parent-child transmission of value orientations: An extended twin family study. Child Development, 87, 270-284. https://doi.org/10.1111/cdev.12452

Kaplan H. S., Bock J. A., \& Hooper P. L. (2015). Fertility theory: Embodied-capital theory of life history evolution. In Neil Smelser (Ed.), International Encyclopedia of the Social \& Behavioral Sciences (pp. 28-34). Oxford, UK: Elsevier. https://doi.org/10. 1016/B0-08-043076-7/02225-7

Kaplan, H., Lancaster, J., \& Robson, A. (2003). Embodied capital and the evolutionary economics of the human life span. Population and Development Review, 29, 152-182.

Kell, H. J., Lubinski, D., \& Benbow, C. P. (2013). Who rises to the top? Early indicators. Psychological Science, 24, 648-659. https://doi. org/10.1177/0956797612457784

Kenrick, D. T., Griskevicius, V., Neuberg, S. L., \& Schaller, M. (2010). Renovating the pyramid of needs: Contemporary extensions built upon ancient foundations. Perspectives on Psychological Science, 5, 292-314. https://doi.org/10.1177/1745691610369469

Kesebir, S., Graham, J., \& Oishi, S. (2010). A theory of human needs should be human-centered, not animal-centered: Commentary on Kenrick et al. (2010). Perspectives on Psychological Science, 5, 315-319. https://doi.org/10.1177/1745691610369470

Ketelaar, T., Tung, Au., \& W. . (2003). The effects of feelings of guilt on the behaviour of uncooperative individuals in repeated social bargaining games: An affect-as-information interpretation of the role of emotion in social interaction. Cognition and Emotion, 17, 429-453. https://doi.org/10.1080/02699930143000662

Kievit, R. A., Romeijn, J. W., Waldorp, L. J., Wicherts, J. M., Scholte, H. S., \& Borsboom, D. (2011). Mind the gap: a psychometric approach to the reduction problem. Psychological Inquiry, 22, 67-87. https://doi.org/10.1080/1047840X.2011.550181

Kleisner, K., \& Tureček, P. (2017). Cultural and biological evolution: What is the difference? Biosemiotics, 10, 127-130. https://doi. org/10.1007/s12304-017-9284-9

Kordsmeyer, T. L., Hunt, J., Puts, D. A., Ostner, J., \& Penke, L. (2018). The relative importance of intra-and intersexual selection on human male sexually dimorphic traits. Evolution and Human Behavior, 39, 424-436. https://doi.org/10.1016/j.evolhumbehav. 2018.03.008

Kosova, G., Abney, M., \& Ober, C. (2010). Heritability of reproductive fitness traits in a human population. Proceedings of the National Academy of Sciences, 107, 1772-1778. https://doi.org/10.1073/ pnas.0906196106

Krems, J. A., \& Conroy-Beam, D. (2020). First tests of Euclidean preference integration in friendship: Euclidean friend value and power of choice on the friend market. Evolution and Human Behavior, 41, 188-198. https://doi.org/10.1016/j.evolhumbehav. 2020.02.003

Kristof-Brown, A., \& Guay, R. P. (2011). Person-environment fit. In S. E. Zedeck (Ed.), APA Handbook of industrial and organizational psychology (Vol 3. Maintaining, expanding, and contracting the 
organization, pp. 3-50). Washington, DC, US: American Psychological Association. https://doi.org/10.1037/12171-001

Lakens, D., Scheel, A. M., \& Isager, P. M. (2018). Equivalence testing for psychological research: A tutorial. Advances in Methods and Practices in Psychological Science, 1, 259-269. https://doi.org/ $10.1177 / \% 2 F 2515245918770963$

Laland, K. N., Odling-Smee, J., \& Feldman, M. W. (2000). Niche construction, biological evolution, and cultural change. Behavioral and Brain Sciences, 23, 131-146. https://doi.org/10.1017/ S0140525X00002417

Lalumière, M. L., Harris, G. T., Quinsey, V. L., \& Rice, M. E. (2005). The causes of rape: Understanding individual differences in male propensity of sexual aggression. American Psychological Association.

Lancaster, J. B., \& Kaplan, H. S. (2010). Embodied capital and extra-somatic wealth in human evolution. In M. P. Muehlenbein (Ed.). Human evolutionary biology (pp. 439-455). Cambridge, UK: Cambridge University Press. https://doi.org/10. 1017/CBO9780511781193.032

Lassek, W. D., \& Gaulin, S. J. (2009). Costs and benefits of fat-free muscle mass in men: Relationship to mating success, dietary requirements, and native immunity. Evolution and Human Behavior, 30, 322-328. https://doi.org/10.1016/j.evolhumbehav.2009. 04.002

Lin, N. (1999). Social networks and status attainment. Annual Review of Sociology, 25, 467-487. https://doi.org/10.1146/annurev.soc. 25.1.467

Lin, N. (2000). Inequality in social capital. Contemporary Sociology, 29, 785-795. https://doi.org/10.2307/2654086

Lin, N. (2001). Social capital: A theory of social structure and action. Cambridge University Press. https://doi.org/10.1017/ CBO9780511815447

Low, C. (2017). A "reproductive capital" model of marriage market matching (Working Paper). Retrieved from https://assets. wharton.upenn.edu/ corlow/research.html

Lukaszewski, A. W., \& Roney, J. R. (2011). The origins of extraversion: Joint effects of facultative calibration and genetic polymorphism. Personality and Social Psychology Bulletin, 37, 409-421. https://doi.org/10.1177/0146167210397209

Lyubomirsky, S., \& Boehm, J. K. (2010). Human motives, happiness, and the puzzle of parenthood: Commentary on Kenrick et al. (2010). Perspectives on Psychological Science, 5, 327-334. https://doi.org/ $10.1177 / 1745691610369473$

Lyubomirsky, S., King, L., \& Diener, E. (2005). The benefits of frequent positive affect: Does happiness lead to success? Psychological Bulletin, 131, 803. https://doi.org/10.1037/0033-2909. 131.6.803

Marsden, P. V., \& Gorman, E. H. (2001). Social networks, job changes, and recruitment. In I. Berg \& A. L. Kalleberg (Eds.), Sourcebook of Labor Markets. Plenum Studies in Work and Industry (pp. 467-502). Springer, Boston, MA.

Maslow, A. H. (1943). A theory of human motivation. Psychological Review, 50, 370-396.

Maslow, A. H. (1958). A dynamic theory of human motivation. In C. L. Stacey \& M. DeMartino (Eds), Understanding human motivation (pp. 26-47). Cleveland, OH: Howard Allen Publishers. https:// dx.doi.org/https://doi.org/10.1037/11305-004

Međedović, J., \& Kovačević, U. (2020). Personality as a state-dependent behavior: Do childhood poverty and pregnancy planning moderate the link between personality and fitness? Personality and Individual Differences, 154, 109625. https://doi.org/10. 1016/j.paid.2019.109625

Međedović, J., Šoljaga, M., Stojković, A., \& Gojević, I. (2018). Revealing complex relations between personality and fitness: HEXACO personality traits, life-time reproductive success and the age at first birth. Personality and Individual Differences, 129, 143-148. https://doi.org/10.1016/j.paid.2018.03.014

Minasny, B., Hartemink, A. E., McBratney, A., \& Jang, H. J. (2013). Citations and the $\mathrm{h}$ index of soil researchers and journals in the Web of Science, Scopus, and Google Scholar. PeerJ, 1. https:// doi.org/10.7717/peerj.183

Nesse, R. M. (1994). An evolutionary perspective on substance abuse. Ethology and Sociobiology, 15, 339-348. https://doi.org/10. 1016/0162-3095(94)90007-8

Nettle, D. (2002a). Height and reproductive success in a cohort of British men. Human Nature, 13, 473-491. https://doi.org/10.1007/ s12110-002-1004-7

Nettle, D. (2002b). Women's height, reproductive success and the evolution of sexual dimorphism in modern humans. Proceedings of the Royal Society of London B: Biological Sciences, 269, 1919-1923. https://doi.org/10.1098/rspb.2002.2111

Nettle, D. (2005). An evolutionary approach to the extraversion continuum. Evolution and Human Behavior, 26, 363-373. https:// doi.org/10.1016/j.evolhumbehav.2004.12.004

Neuberg, S. L., Kenrick, D. T., Maner, J. K., \& Schaller, M. (2005). From evolved motives to everyday mentation: Evolution, goals, and cognition. In S. Laham, K. Williams, \& J. P. Forgas (Eds.), Social motivation: Conscious and unconscious processes (pp. 133-152). New York, NY, US: Cambridge University Press. https://doi.org/10.1017/CBO9780511735066.010

Orr, H. A. (2009). Fitness and its role in evolutionary genetics. Nature Reviews Genetics, 10, 531-539. https://doi.org/10.1038/nrg2603

Paech, N. (2012). Liberation from excess: The road to a post-growth economy. Munich, Germany: oekom verlag.

Peterson, C., \& Park, N. (2010). What happened to self-actualisation? Commentary on Kenrick et al. (2010). Perspectives on Psychological Science, 5, 320-322. https://doi.org/10.1177/17456 91610369471

Pflüger, L. S., Oberzaucher, E., Katina, S., Holzleitner, I. J., \& Grammer, K. (2012). Cues to fertility: Perceived attractiveness and facial shape predict reproductive success. Evolution and Human Behavior, 33, 708-714. https://doi.org/10.1016/j.evolhumbehav.2012. 05.005

Pinker, S. (1999). How the mind works. New York, NY: W. W. Norton \& Company.

Popper, K. R. (1959). Logic of Scientific Discovery. Basic Books.

Puts, D. (2016). Human sexual selection. Current Opinion in Psychology, 7, 28-32. https://doi.org/10.1016/j.copsyc.2015.07.011

Puts, D. A., Bailey, D. H., \& Reno, P. L. (2015). Contest competition in men. In D. M. Buss (Vol. Ed.), The handbook of evolutionary psychology, Volume 1: Foundations (pp. 385-402). Hoboken, New Jersey: John Wiley \& Sons. https://doi.org/10. 1002/9781119125563.evpsych113

Raine, A., Brennan, P., Mednick, B., \& Mednick, S. A. (1996). High rates of violence, crime, academic problems, and behavioral problems in males with both early neuromotor deficits and unstable family environments. Archives of General Psychiatry, 53, 544-549. https://doi.org/10.1001/archpsyc.1996. 01830060090012

Rantala, M. J., Moore, F. R., Skrinda, I., Krama, T., Kivleniece, I., Kecko, S., \& Krams, I. (2012). Evidence for the stress-linked immunocompetence handicap hypothesis in humans. Nature Communications, 3, 694. https://doi.org/10.1038/ncomms1696

Richerson, P. J., \& Boyd, R. (2005). Not by genes alone. The University of Chicago Press.

Rhodes, G., Simmons, L. W., \& Peters, M. (2005). Attractiveness and sexual behavior: Does attractiveness enhance mating success? Evolution and Human Behavior, 26, 186-201. https://doi.org/10. 1016/j.evolhumbehav.2004.08.014 
Rowland, D. T. (2007). Historical trends in childlessness. Journal of Family Issues, 28, 1311-1337. https://doi.org/10.1177/ 0192513X07303823

Savage, J., \& Kanazawa, S. (2002). Social capital, crime, and human nature. Journal of Contemporary Criminal Justice, 18, 188-211. https://doi.org/10.1177/1043986202018002005

Savage, J., \& Kanazawa, S. (2004). Social capital and the human psyche: why is social life "capital"?. Sociological Theory, 22, 504524. https://doi.org/10.1111/j.0735-2751.2004.00231.x

Schaller, M., Neuberg, S. L., Griskevicius, V., \& Kenrick, D. T. (2010). Pyramid power: A reply to commentaries. Perspectives on Psychological Science, 5, 335-337. https://doi.org/10.1177/ 1745691610369474

Schönbrodt, F. D., \& Gerstenberg, F. X. (2012). An IRT analysis of motive questionnaires: The unified motive scales. Journal of Research in Personality, 46, 725-742. https://doi.org/10.1016/j. jrp.2012.08.010

Schülke, O., Bhagavatula, J., Vigilant, L., \& Ostner, J. (2010). Social bonds enhance reproductive success in male macaques. Current Biology, 20, 2207-2210. https://doi.org/10.1016/j.cub.2010.10. 058

Sear, R., Lawson, D. W., \& Dickins, T. E. (2007). Synthesis in the human evolutionary behavioural sciences. Journal of Evolutionary Psychology, 5, 3-28. https://doi.org/10.1556/JEP.2007.1019

R Sear DW Lawson H Kaplan MK Shenk 2016 Understanding variation in human fertility: What can we learn from evolutionary demography? Philosophical Transactions of the Royal Society B 371 https://doi.org/10.1098/rstb.2015.0144

Simpson, J. A., Griskevicius, V., \& Kim, J. S. (2011). Evolution, life history theory, and personality. In L. M. Horowitz \& S. Strack (Eds.), Handbook of interpersonal psychology: Theory, research, assessment, and therapeutic interventions (pp. 75-89). New York: Wiley. https://doi.org/10.1002/9781118001868.ch5

Smith, B. R., \& Blumstein, D. T. (2008). Fitness consequences of personality: A meta-analysis. Behavioral Ecology, 19, 448-455. https://doi.org/10.1093/beheco/arm144

Statista. (2018). Deaths by homicide per 100,000 resident population in the U.S. from 1950 to 2015. Retrieved from https:// www.statista.com/statistics/187592/death-rate-from-homicidein-the-us-since-1950.

Steiner, U. K., \& Tuljapurkar, S. (2012). Neutral theory for life histories and individual variability in fitness components. Proceedings of the National Academy of Sciences, 109, 4684-4689. https://doi. org/10.1073/pnas.1018096109

Stulp, G., Pollet, T. V., Verhulst, S., \& Buunk, A. P. (2012a). A curvilinear effect of height on reproductive success in human males. Behavioral Ecology and Sociobiology, 66, 375-384. https://doi. org/10.1007/s00265-011-1283-2

Stulp, G., Verhulst, S., Pollet, T. V., \& Buunk, A. P. (2012b). The effect of female height on reproductive success is negative in western populations, but more variable in non-western populations. American Journal of Human Biology, 24, 486-494. https://doi. org/10.1002/ajhb.22252

Strouts, P. H., Brase, G. L., \& Dillon, H. M. (2017). Personality and evolutionary strategies: The relationships between HEXACO traits, mate value, life history strategy, and sociosexuality. Personality and Individual Differences, 115, 128-132. https://doi.org/10.1016/j.paid. 2016.03.047

Sugiyama, L. S. (2015). Physical attractiveness in adaptationist perspective. In D. M. Buss (Ed.), The handbook of evolutionary psychology (Vol. 1: Foundations; pp. 292-343). Hoboken, New Jersey: John Wiley \& Sons. https://doi.org/10.1002/ 9781119125563.evpsych112

te Velde, E. R., \& Pearson, P. L. (2002). The variability of female reproductive ageing. Human Reproduction Update, 8, 141-154. https://doi.org/10.1093/humupd/8.2.141
Tooby, J., \& Cosmides, L. (1990). The past explains the present: Emotional adaptations and the structure of ancestral environments. Ethology and Sociobiology, 11, 375-424. https://doi.org/10. 1016/0162-3095(90)90017-Z

Tooby, J., Cosmides, L., Sell, A., Lieberman, D., \& Sznycer, D. (2008). Internal regulatory variables and the design of human motivation: A computational and evolutionary approach. In A. J. Elliot (Ed.), Handbook of approach and avoidance motivation (pp. 251-271). Lawrence Erlbaum Associates.

Townshend, J., \& Duka, T. (2001). Attentional bias associated with alcohol cues: Differences between heavy and occasional social drinkers. Psychopharmacology (berl), 157, 67-74. https://doi.org/10.1007/ s002130100764

Turan, B., Guo, J., Boggiano, M. M., \& Bedgood, D. (2014). Dominant, cold, avoidant, and lonely: Basal testosterone as a biological marker for an interpersonal style. Journal of Research in Personality, 50, 84-89. https://doi.org/10.1016/j.jrp.2014.03.008

Vall, G., Gutiérrez, F., Peri, J. M., Gárriz, M., Baillés, E., Garrido, J. M., \& Obiols, J. E. (2016). Seven dimensions of personality pathology are under sexual selection in modern Spain. Evolution and Human Behavior, 37, 169-178. https://doi.org/10.1016/j. evolhumbehav.2015.10.004

van Schaik, C. P., \& Burkart, J. M. (2010). Mind the gap: Cooperative breeding and the evolution of our unique features. In P. M. Kappeler \& J. Silk (Eds.), Mind the gap: Tracing the origins of human universals (pp. 477-496). Berlin, Germany: Springer. https://doi.org/10.1007/978-3-642-02725-3_22

van Vugt, M., \& Tybur, J. M. (2015). The evolutionary foundations of hierarchy: Status, dominance, prestige, and leadership. In D. M. Buss (Vol. Ed.), The Handbook of Evolutionary Psychology, Vol. II: Integrations (pp. 788-809). Hoboken, NJ: Wiley. https://doi. org/10.1002/9781119125563.evpsych232

Vazire, S. (2006). Informant reports: A cheap, fast, and easy method for personality assessment. Journal of Research in Personality, 40, 472-481. https://doi.org/10.1016/j.jrp.2005.03.003

von Borell, C. J., Kordsmeyer, T. L., Gerlach, T. M., \& Penke, L. (2019). An integrative study of facultative personality calibration. Evolution and Human Behavior, 40, 235-248. https://doi. org/10.1016/j.evolhumbehav.2019.01.002

von Hippel, W., Lakin, J. L., \& Shakarchi, R. J. (2005). Individual differences in motivated social cognition: The case of selfserving information processing. Personality and Social Psychology Bulletin, 31, 1347-1357. https://doi.org/10.1177/\% 2F0146167205274899

von Rueden, C., Gurven, M., \& Kaplan, H. (2008). The multiple dimensions of male social status in an Amazonian society. Evolution and Human Behavior, 29, 402-415. https://doi.org/10. 1016/j.evolhumbehav.2008.05.001

von Rueden, C., Gurven, M., \& Kaplan, H. (2011). Why do men seek status? Fitness payoffs to dominance and prestige. Proceedings of the Royal Society of London B: Biological Sciences, rspb20102145. https://doi.org/10.1098/rspb.2010.2145

von Rueden, C. R., \& Jaeggi, A. V. (2016). Men's status and reproductive success in 33 nonindustrial societies: Effects of subsistence, marriage system, and reproductive strategy. Proceedings of the National Academy of Sciences, 113, 10824-10829. https://doi. org/10.1073/pnas.1606800113

von Rueden, C. R., Lukaszewski, A. W., \& Gurven, M. (2015). Adaptive personality calibration in a human society: Effects of embodied capital on prosocial traits. Behavioral Ecology, 26, 1071-1082. https://doi.org/10.1093/beheco/arv051

Wiggins, J. S. (1982). Circumplex models of interpersonal behavior in clinical psychology. In P. C. Kendall \& J. N. Butcher (Eds.), 
Handbook of research methods in clinical psychology (pp. 183221). Wiley.

Wiggins, J. S., Trapnell, P., \& Phillips, N. (1988). Psychometric and geometric characteristics of the Revised Interpersonal Adjective Scales (IAS-R). Multivariate Behavioral Research, 23, 517-530. https://doi.org/10.1207/s15327906mbr2304_8

Witte, E. H., \& Zenker, F. (2017). From discovery to justification: Outline of an ideal research program in empirical psychology. Frontiers in Psychology, 8, 1847. https://doi.org/10.3389/fpsyg. 2017.01847

Yao, S., Långström, N., Temrin, H., \& Walum, H. (2014). Criminal offending as part of an alternative reproductive strategy:
Investigating evolutionary hypotheses using Swedish total population data. Evolution and Human Behavior, 35, 481-488. https:// doi.org/10.1016/j.evolhumbehav.2014.06.007

Zethraeus, N., Dreber, A., Ranehill, E., Blomberg, L., Labrie, F., von Schoultz, B., Johannesson, M., \& Hirschberg, A. L. (2016). Combined oral contraceptives and sexual function in women-A double-blind, randomized, placebo-controlled trial. The Journal of Clinical Endocrinology \& Metabolism, 101, 4046-4053. https:// doi.org/10.1210/jc.2016-2032

Publisher's Note Springer Nature remains neutral with regard to jurisdictional claims in published maps and institutional affiliations. 